\title{
EL DISCURSO DE MANIPULACIÓN BURGUÉS A PARTIR DEL ANÁLISIS DEL ORDEN SOCIAL EN LAS OBRAS "LA REGENTA" DE LEOPOLDO ALAS Y "ENTRE NARANJOS” DE BLASCO IBÁÑEZ
}

\author{
THE DISCOURSE OF BOURGEOIS MANIPULATION BASED ON THEANALYSIS OF \\ THE SOCIAL ORDER IN THE NOVELS "LA REGENTA" OF \\ LEOPOLDO ALAS AND "ENTRE NARANJOS” OF BLASCO IBANEEZ
}

\section{RESUMEN}

Este trabajo se propone señalar la forma en que los procesos de manipulación están presentes en las obras "La Regenta" de Leopoldo Alas y "Entre Naranjos" de Blasco Ibáñez. Se detalla la forma en que en estas dos novelas hay un orden social pensado en la integración de todos como iguales y la forma utilizada por la burguesía para construir una plusvalía, no sólo económica, sino simbólica y cultural. El presente artículo hurga en la manipulación presente también desde las figuras de los narradores, además a lo largo del texto se fundamenta cómo la desintegración está vista, para el orden del siglo XIX, como algo negativo y cómo desde un orden socialmente establecido y perfectamente identificado hay figuras claves que cortan los procesos de diferenciación.

Palabras clave: burguesía; integración; manipulación; orden social; procesos de diferenciación.

\begin{abstract}
This work intends to point out the way the handling processes are present in the novels "La Regenta" of Leopoldo Alas and "Entre Naranjos" of Blasco Ibáñez. Details the way in which these two novels there is a social order thought the integration of everyone as equals and the way in which the bourgeoisie has built a surplus value, which is not only economic, but symbolic and cultural appreciation. This article delves into this manipulation also from the figures of the narrators. In addition, throughout the text it delves into how the breakup is view for the order of the 19th century as something negative and how from a socially established order and perfectly identified there are key figures in cutting processes of differentiation.
\end{abstract}

Keywords: Social order; bourgeoisie; handling; integration; differentiation processes. 


\section{INTRODUCCIÓN}

Refiriéndose a las burguesías parisinas del siglo XX, Bourdieu (1983) aseguraba que quien rompe el discurso monolítico va a ser castigado, porque su error está justamente en conocerse a sí mismo y no reconocerse como parte integrante del grupo. En este contexto, analizar el binomio de la relación integración y desintegración es clave para entender el mecanismo interno del funcionamiento de las novelas "La Regenta" de Leopoldo Alas y "Entre Naranjos" de Vicente Blasco Ibáñez.

El criterio bourdiano es pertinente referirlo porque en las obras analizadas existe un proceso de identificación que tiene relación con el binomio integración / desintegración. En "La Regenta" es la misma Ana Ozores, porque en ella prima la singularidad, el verse distinta, que luego lo muta en una tragedia.

En el caso de "Entre Naranjos" este proceso es posible apreciarlo en Rafael Brull, el personaje principal, que pasa por una etapa de desintegración de entrada. Rafael lleva el nombre de un pintor del renacimiento y su familia espera que se realice como abogado ejerciendo el cacicazgo y que acumule más dinero casándose con la joven apropiada. El tema está en el interior de ambos: Ana y Rafael, y sus conflictos amorosos. Ana no sabe qué es lo que quiere cuando aparece una figura tan voluptuosa como la de Álvaro Mesía. En cambio Rafael encontró donde poner su deseo y lo hará en la figura de Leonora, su amada.

\section{METODOLOGÍA}

Uno de los abordajes para emprender una investigación en ciencias sociales es el análisis cualitativo. Se trata de aplicar un proceso dinámico, que pone énfasis en el sentido del texto y uno de sus propósitos es describir un fenómeno lingüístico. Según Vasilachis (2006), este enfoque metodológico se caracteriza por su rigor y por su flexibilidad, por su sistematicidad y por su creatividad, por su seriedad y reflexividad. A partir de esta perspectiva, se realiza un acercamiento al carácter subjetivo y a las particularidades de las obras de Leopoldo Alas y Blasco Ibáñez.

En este sentido, el trabajo investigativo realizado se fundamentó en una metodología que según Rossman y Rallis (1998), empieza con la recogida de datos y termina cuando se redacta el estudio, es decir que aún en la escritura el investigador puede continuar analizando datos. En consecuencia, el estudio se basó en el análisis cualitativo de las partes más significativas del texto, que a criterio del autor, constituyen referentes para indagar en el binomio integración / desintegración, presente en las novelas españolas consideradas. A partir de este análisis cualitativo también se exploró la caracterización de los narradores de estas obras.

A criterio de Creswell (1998), el análisis cualitativo es un proceso interpretativo de indagación basado en la construcción de una imagen compleja y holística por parte del investigador. Este enfoque no indaga en la repetición o en la frecuencia de aparición de ciertos aspectos, sino que busca la presencia, el significado y el valor de los temas que surgen. Es, precisamente, lo que se ha pretendido esbozar con el estudio de aspectos como el orden social, presente en las obras "La Regenta" y "Entre Naranjos".

\section{RESULTADOS Y DISCUSIÓN}

\section{Ser distinto es ir hacia el camino de la exclusión}

En las obras analizadas hay un centro constitutivo, ¿qué sucede cuando uno se comienza a apartar y a construirse como ser distinto?, 
pues inevitablemente se produce la fragmentación del centro y esto le pasa a los respectivos protagonistas de las novelas referidas. Ni Ana Ozores en "La Regenta", ni Rafael Brull en "Entre Naranjos" se sienten cómodos con sus iguales y buscan su propio camino que los vuelve distintos, pero al mismo tiempo en esa búsqueda se excluyen de sus grupos sociales.

Con las crisis de Ana, es decir, con sus tentaciones en la soledad, comprueba que le teme a la desintegración; en comparación a ella, Leonora, la amante de Rafael, es distinta. Leonora cumple el rol perfecto que el orden burgués tiene en la cabeza, en cierta manera el grupo limita y permite no crecer; por su parte, Rafael se funde en la naturaleza, está predispuesto a encontrarla.

Otros personajes explican este criterio, por ejemplo, en "La Regenta", el Magistral pone sus garras sobre todo lo que se le acerca y le interesa, le gusta saber la vida de los otros y hay en él un lado lascivo, pese a su condición de religioso, su trayectoria ayuda a entenderlo más: él fue un pastor de cabras y se esforzó en culminar sus estudios.

Esto le da al Magistral una tremenda voluntad, si no hubiera sido por esta cualidad, no hubiera llegado donde está, sin embargo, en el fondo su madre lo domina y él busca dominar a Ana Ozores, por otro lado, el grupo social de "Entre Naranjos" siente que alguien es diferente a ellos, por eso no aprecian que Rafael Brull busque lo diverso, ni que proyecte caminos que buscan lo distinto, entonces este grupo busca de alguna manera rehacer la propiedad simbólica.

En cierta forma, en "La Regenta", el personaje del Magistral guarda relación con Rafael Brull. El Magistral no es un ser auténtico, se trata de un ser atrapado por la voluntad de dominio, que ha construido una carrera dominando. En cambio lo que le falta a Rafael es voluntad de dominio, característica que viene con él dado que es el cacique, pero en realidad no es lo que le interesa, es un alma poética, mágica; en una clave schilleriana se podría decir que es un aprendiz de un alma bella que busca un papel en la vida sin salir de la tradición.

En este contexto burgués hay dos personajes que intentan ser distintos dentro de un orden que quiere domesticarlos, pero que no tienen capacidades emocionales para hacerlo. En la novela "Entre Naranjos" es el caso de Rafael a quien le falta voluntad; en el caso de "La Regenta", es la propia Ana Ozores, a quien le falta una emocionalidad más coherente, porque ha sido marcada desde la infancia. Rafael también ha sido marcado, pero en su infancia ha sido mimado, festejado y por dentro es un ser más libre, en cambio la Regenta ha tenido una infancia atroz, que la ha privado de la madre y no ha recibido ningún tipo de calor maternal: nunca pudo llenar ese vacío.

\section{La manipulación del narrador}

Se podría decir que hay un sesgo manipulador que atraviesa ambas novelas. El narrador también manipula la realidad, se mete en el interior de los personajes, los escudriña, ambos relatos tienen la construcción de dos narradores burgueses, donde todo es manipulable, el narrador manipula al lector y los personajes, mientras que la sociedad manipula al individuo y le marca lo que tiene que hacer. Hay un atisbo de manipulación cuando La Regenta en Semana Santa aparece con los pies heridos, todos saben que eso raya en el mal gusto, en cierta obscenidad y Ana Ozores nota que puede extraviarse.

En la obra de Leopoldo Alas es posible notar cómo la iglesia ejerce sobre la ciudad de Vetusta cierto nivel de manipulación en dos grupos políticos que pactan espacios de 
conciliación con ella. El agente de esos pactos es el Magistral, aquellos que no se prestan a los juegos de poder se los trata como idiotas y su madre ha construido su propio espacio de poder, el Magistral intenta dominar a La Regenta y no la ve como otro, sino como una extensión de sí mismo.

En el capítulo tercero de la obra, la Regenta intenta manipular, pero es un juego que no le sale, porque el marido de ella, don Víctor Quintanar, no es susceptible de ser manipulado. Al esposo de Ana Ozores se lo puede manipular en un discurso que no sea de la emoción, ni de los sentimientos, porque en el mundo de lo cotidiano está bloqueado, tiene carencias afectivas que no puede proyectar en la vida diaria, en tal sentido, Don Víctor sublima su parte emocional, cuando Ana en la habitación intenta que tengan relaciones, él sale huyendo porque no puede.

Bourdieu (1983), asegura que la permanencia en los grupos sociales tiene límites y es un signo de distinción, sostiene que el intercambio transforma las cosas en signos de reconocimiento. Esto ocurre también cuando dos personas, marido y mujer, deciden unirse. En "La Regenta", Don Víctor cumple perfectamente la visión que tiene el burgués del matrimonio, mientras todo sea un juego de apariencia en la relación, supone que es correcto y engrandece que otro hombre coquetee a su mujer, porque enaltece la estima del marido y en ese juego entra perfectamente y vive con tanta felicidad, que no se da cuenta lo que ese juego le causa a Ana, porque simplemente es incapaz de mirarla, además, los personajes que Leopoldo Alas recrea, como los marqueses de Vellagana, el marquesito Visitación y Obdulia son personajes que están felices en su juego de rol, en el que todos conocen cuáles son los signos de distinción y cuáles los de infamia.
En lo que respecta a "Entre Naranjos", se puede notar cómo exteriormente la imagen pública de Rafael Brull no ha perdido nada, al contrario su figura se ha cimentado, sin embargo en "La Regenta", la imagen pública de Ana ha quedado muy mal, su yo profundo queda perdido en una situación de desconocimiento de sí misma, los hechos la han superado, la Regenta no tiene capacidad de manipulación, en una sociedad donde la manipulación tiene un rol preponderante.

Sin embargo, si Rafael Brull no se hubiera encontrado con Leonora, quizá hubiera tratado de entusiasmarse con Remedios, quien fuera su esposa, porque es una chica agradable, cumple perfectamente con el rol, es la novia burguesa por excelencia: mujer débil, que se preocupa de los problemas familiares, que le va a permitir a él, interpretar siempre el rol masculino. Remedios, en resumen, es dibujada como una mujer cuya felicidad está anclada en el desenlace del matrimonio y la familia.

El drama de Rafael Brull está dado para construir una situación de felicidad, pero no la puede terminar de edificar, pese a que tuvo hijos, no hubo nada interesante en su vida. Ha logrado hacer de sí el modelo expreso que la vida tenía para él, es decir tiene una familia que cultiva la integración social; sobre esto es necesario considerar que:

Una gran cantidad de indicios induce a creer que la familia burguesa sigue cultivando su integración social, que es la condición primordial de su aporte a la perpetuación de su capital social y de su capital simbólico y, por ello, de su capital económico. (Bourdieu 2011:44)

Ana Ozores, la protagonista de la novela de Leopoldo Alas, no quiere caer en el adulte- 
rio, sin embargo, la Regenta se ha salido del papel y ha producido un escándalo, hay una represión de lo sensual, porque lo que hay detrás de todo esto, es el escándalo, lo que genera esta situación es que alguien sea defenestrado y esto ha provocado una gran ruptura; la Regenta, después de darse a conocer los hechos, no tiene lugar en este orden burgués.

Rafael Brull, por el contrario, es un burgués atípico, él va a disfrutar de esta posición, de participar en la política, se viste bien, disfruta de la belleza, en su casa, a los suyos no les importa lo que hiciera o decidiera, les importaba que él estuviera ahí, pues con él ahí, el prestigio de la familia se mantiene inalterable.

El burgués construye el prestigio de forma diferente al aristócrata, había que tener el prestigio y para ello había que tener una plusvalía material para aportar a ese prestigio. El burgués acumula capital como sea, incluso extorsionando, por ejemplo, el abuelo de Rafael fue un prestamista, estafador de unos campesinos, o sea que: en todo caso, se trata de la justificación del capital a como dé lugar.

Dice Bourdieu (2011), que el momento sombrío del burgués es la acumulación del capital, luego que ese capital está reunido, hay que dotarlo de prestigio; el burgués pierde con el tiempo la conciencia de su fase inicial. Los Brull son gente de altura, cuando muere el padre de Rafael muere una etapa.

El padre de Rafael no le es antipático, venía de un linaje de caciques, va a poder votar a un Brull y la aptitud de Rafael, lo sitúan como el mejor, ve en su actitud de liberador, la forma de llegar a Leonora. Cada acción de Rafael delante de sus vecinos lo empuja al rol que no eligió para sí, sin embargo, hay un problema que viene de su infancia prolonga- da, que le impide desempeñar roles en grupo, no se siente cómodo en el Casino, ni en Madrid, siempre donde hay un grupo, Rafael no se puede desempeñar con comodidad.

En algunos momentos traen al Casino, alguien para que juegue con Rafael, él es un hijo único, mimado y muy cuidado, a quien le cuesta mucho integrarse en una relación de más de dos, no tiene problema cuando habla con Don Andrés, cuando habla con Cupido, cuando se dirige a una masa indiferente, pero cuando tiene que estar en una relación de pares en la corte o en el Casino se aburre, no encuentra interés, hasta cuando ya tiene una familia con Remedios él se aburre, puede estar en una relación de dos muy a gusto, pero no en una relación de grupo.

Cuando Rafael Brull está solo ante la naturaleza siente calma, busca lo que buscaba el pintor: la armonía, el equilibrio, pero esa tranquilidad no la va a encontrar en el huerto de Leonora, esa naturaleza lo ciega y eso también pierde a Leonora, porque ella se da cuenta enseguida de que Rafael es muy tierno, que es un niñito, muchas veces usa el diminutivo, que refleja que es un adulto con una carcasa, ella lo ve y lo sabe inmediatamente. El encuentro en el huerto esa noche de primavera es una pulsión natural, los dos se unen por la pulsión de la naturaleza, los dos son sensibles a la llamada del elemento natural.

En "La Regenta", Ana Ozores se siente confundida, ella cree que Álvaro Mesía, su amante, la puede ayudar a salir de la vida monótona que lleva, pero él es un hombre que se acerca a ella para cumplir el rol que le tiene asignado el grupo, que es el rol de Don Juan, en consecuencia tampoco abre su interioridad. Lo retrata muy bien Leopoldo Alas cuando dice que Mesía no tiene casa, la 
casa psicológicamente es la cabeza de una persona, incluso puede ser una habitación, pero Mesía vive en hoteles y este rasgo también está hablando de la falta de interioridad, porque es una persona que siempre está de paso, no reconoce nada como su casa.

En "Entre Naranjos", Rafael Brull vive un drama, cuya esencia no es que sienta deseo por Leonora, sino que luego de haberla conocido quiera casarse, eso significa transgredir el orden y él como buen burgués quiere ponerla en un lugar, pero no quiere darle un lugar de desdoro, sino que quiere darle el lugar central, pero para eso tiene que alejarla e incorporarla de nuevo en el grupo. Él no tiene la voluntad para hacerlo porque no se relaciona bien con el grupo y Leonora se entusiasma con una utopía y luego sufre mucho cuando Rafael no regresa jamás a sus brazos.

Estas obras están contadas por un narrador burgués que condena a los personajes, por ejemplo, Vicente Blasco Ibáñez, el autor de "Entre Naranjos", caracteriza a Rafael Brull como un autómata, un muñequito de cuerda, que cuando se suelta, se puede volver a recoger. Leonora se da cuenta de ello en un momento y por eso no se quiere enamorar de él, pues como mujer de mundo ha sufrido, pero la pulsión y el enamoramiento también le llegan a ella y entonces ella se convierte en víctima, él deja en el camino una víctima, no puede luchar porque tiene una carencia interior, tiene carencias infantiles muy fuertes. Rafael no es una persona con malas intenciones, pero cuando está a punto de dar el paso para reconocerse como individuo, cuando está a punto de conocer el mundo acompañado de su amor Leonora, simplemente no lo puede hacer.

Hay diferencias entre Remedios y Leonora, Remedios, la mujer de Rafael, tiene la belle- za ingenua, natural, lineal, no es más que la esposa adinerada vestida a la moda de la burguesía europea, sin embargo, a ello no aspira Rafael, él aspira a una mujer que le pueda dar lo que no tiene: sofisticación, conocimiento de Europa. En Rafael hay un decantarse muy fuerte por los otros, Leonora en cambio vive en un mundo artístico, en un mundo donde las clases emergentes copiaban a la burguesía.

\section{Los discursos y la caracterización de los personajes}

Toda la permisibilidad con la cual se ha movido el occidente burgués está basada en la eliminación de cuatro discursos: el discurso del deseo, el discurso de la emoción, el discurso del poder y el discurso de la locura, son discursos que occidente ha tratado de eliminar con la razón, la causalidad y la verdad.

El sistema de construcción del romanticismo es un sistema de represión, el arte, por su parte, cumple una función de transferencia de los deseos reprimidos, es lo que se espera de una sociedad que da ciertas licencias sin salir del orden. En tal sentido, ese pintoresco personaje de "La Regenta" que es Obdulia, se permite ciertas libertades, en el seno del grupo no diferenciándose de los iguales y viviendo lo que (Foucault 1977) denomina la hipocresía como técnica de poder. Esta hipocresía altera toda la sociedad de Vetusta, la ciudad en la que transcurre la obra de Leopoldo Alas, y mejora su posicionamiento socioeconómico.

De ahí también el hecho de que el punto importante será saber en qué formas, a través de qué canales, deslizándose a lo largo de qué discursos llega el poder hasta las conductas más tenues y más individuales, qué caminos le permiten alcanzar las formas infrecuentes o apenas perceptibles del 
deseo, cómo infiltra y controla el placer cotidiano -todo ello con efectos que pueden ser de rechazo, de bloqueo, de descalificación, pero también de incitación, de intensificación, en suma: las técnicas polimorfas del poder. (Foucault 1977:13)

La cuestión a tener en cuenta es que en ambos personajes (tanto Ana Ozores como Rafael Brull) no ha habido un proceso de desintegración, proceso que implica volver a integrarse. Por ejemplo, el personaje Anna Karennina de Tolstoi en un medio aristocrático, pero con muchos elementos burgueses, es una especie de alma bella, que cuando se entrega a una relación de amantes, llega un momento en que no quiere mantenerse al margen, no pretende camuflarse en el grupo, toma decisiones muy fuertes, Ana Ozores en cambio, se expone y de tanta exposición queda desintegrada.

La desintegración está vista para el orden del siglo XIX como algo negativo, cuando Rafael Brull se quiere individualizar encuentra trabas (sus propios miedos, la figura de su madre) y cuando más se quiere acercar, más se aleja de esta expectativa. En el caso de Rafael la presión del grupo está enmarcada en una burguesía exquisita, donde la censura se manifiesta en las miradas, en el fondo es un personaje lleno de dudas, lo separa la inseguridad, ¿qué seré yo para ella?, se pregunta refiriéndose a Leonora, su amada.

Al mismo tiempo resulta relevante analizar cómo el narrador de "Entre naranjos" caracteriza los rasgos de este personaje:

Él no era indiferente para ella, no le inspiraba antipatía ni odio; de lo contrario, no serían amigos ni le permitiría las continuas visitas. ¿Amor?... Estaba seguro de que no lo sentía por él, pobre infeliz, incapaz de inspirar una pasión a una mujer como ella. Pero que no se resistiera; ya le amaría con el tiempo; él lograría conquistarla en fuerza de cariño y de adoración. ¡Ay! con sólo su amor, había para los dos y para todos los amantes famosos en la historia. Sería su esclavo, la alfombra en que pondría sus pies; el perro, siempre tendido ante ella, con la mirada ardiente de la eterna fidelidad, acabaría por quererle, si no por amor, por gratitud y por lástima. (Blasco 2004:114)

Rafael Brull encuentra en Leonora a una persona que lo quiere, a una mujer que cumple con todo el estereotipo, sin embargo, a medida que ocurren las cosas, va individualizándose, con el tiempo no se olvidaría que es un Brull, probablemente tomaría elementos de esa tradición y los reactualizaría desde otra apertura.

Pero, ¿por qué no puede Rafael completar el camino de la individualización?, porque en el fondo él no tiene voluntad: se ha identificado con lo femenino de su padre, con el lado débil y por tanto, cuando tiene que hacer las cosas de frente y portarse como un adulto, es dominado por su madre y es esta forma de ser de la mamá quien impide que complete el círculo.

El caso de Ana Ozores es peor, la Regenta queda apartada del grupo, hasta un sacristán se atreve a besarla. La imagen final que cierra la novela lo evidencia:

La catedral estaba sola. Las sombras de los pilares y de las bóvedas se iban juntando y dejaban el templo en tinieblas. Celedonio, el acólito afeminado, alto y escuálido, con la sotana corta y sucia, venía de capilla en capilla cerrando verjas. Las llaves del manojo 
sonaban chocando. Llegó a la capilla del Magistral y cerró con estrépito. Después de cerrar tuvo aprensión de haber oído algo allí dentro; pegó el rostro a la verja y miró hacia el fondo de la capilla, escudriñando en la obscuridad. Debajo de la lámpara se le figuró ver una sombra mayor que otras veces... Y entonces redobló la atención y oyó un rumor como un quejido débil, como un suspiro. Abrió, entró y reconoció a la Regenta, desmayada. Celedonio sintió un deseo miserable, una perversión de la perversión de su lascivia: y por gozar un placer extraño, o por probar si lo gozaba, inclinó el rostro asqueroso sobre el de la Regenta y le besó los labios. Ana volvió a la vida rasgando las nieblas de un delirio que le causaba náuseas. Había creído sentir sobre la boca el vientre viscoso y frío de un sapo. (Alas 2005:503)

Este final para la Regenta es algo terrible, no logra ni diferenciarse del grupo, ni seguir siendo santificada por él, la castiga la idea que el grupo tenía de ella. La caída de Ana Ozores, lo que vive en la catedral, propicia que quede en una especie de limbo y tiene que ser estigmatizada por el grupo burgués. El hecho de que Álvaro Mesía, su amante, haya podido tener relaciones con ella destruye su lugar en el grupo, por ello, dejó de ser el tótem, la mujer a la que ningún hombre podía acercarse.

Tanto los protagonistas de "La Regenta" y "Entre Naranjos", Ana Ozores y Rafael Brull, comienzan a recorrer, en el desenlace de las obras, un camino que podría llevarlos a otro derrotero, comienzan a verse diferentes, a cambiar la centralidad, el objetivo de interés.

Aunque Rafael queda dentro del grupo, permanece prácticamente como un cadáver, porque es todo lo que no quisiera ser, él juega el rol del político: habla, pero no cree en nada de lo que hace. Cuando Rafael le pide a Leonora volver, ella le dice que entre los dos no puede haber nunca ninguna relación porque hay un muerto que les impide aproximarse; “¿cuál muerto?”, pregunta él; "aquel amor que mataste", le responde ella. Esa frase marca a Rafael para el resto de su vida, lo cual tiene que ver con una frustración íntima que queda perfectamente señalada con las últimas palabras que le grita Leonora, ante el pedido desesperado de él para que vuelva a su lado:

Si vuelvo, serás uno de mis innumerables amigos; nada más. Y no creas que soy ahora una santa. La misma que antes de conocerte; pero de todos, ¿sabes? del portero del teatro, si es preciso, antes que de ti. Tú eres un muerto... Adiós, Rafael. (Blasco 1904:179)

Para Rafael Brull esto es terrible, porque no ha podido cumplir este proceso de individuación que es la madurez. En Ana Ozores este proceso es similar e igual de trágico, por ello, los caminos de las novelas "La Regenta" y "Entre Naranjos" se entrelazan por medio de sus personajes. Al final de ambas obras, el drama de sus protagonistas se encuentra marcado por las decisiones que adoptaron y que los dejan en la profunda desolación.

\section{CONCLUSIONES}

En las dos novelas analizadas hay un orden social pensado en la integración de todos como iguales, sin embargo, aquí caben dos preguntas: ¿cómo vive una persona que pasa por un proceso de desintegración?, ¿qué sucede cuando uno de estos iguales en verdad es desigual?, de esta manera puede entenderse la exclusión del grupo como un acto de responsabilidad privada, como un 


\section{Unach}

mal uso de las responsabilidades vitales. Tanto en "La Regenta", de Leopoldo Alas, como en "Entre Naranjos", de Vicente Blasco Ibáñez, el pequeño grupo burgués protege, pero también es capaz de destruir, por tanto ahí, en ese proceso, la nueva pequeña burguesía y la burguesía ya consolidada, tienen su espacio.

Con las caracterizaciones presentadas a lo largo del texto, se pretende dar cuenta de que en ambas obras, surge una visión que responde a la realidad española que se cuenta. Se retrata, además, un mundo socio-político que corresponde al tono general de hastío y anquilosamiento de la época, y sobre todo, tanto Leopoldo Alas como Vicente Blasco Ibáñez, brindan un panorama cercano al estilo de vida burgués de finales del siglo XIX.

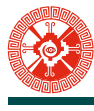

\section{REFERENCIAS \\ BIBLIOGRÁFICAS}

Alas, L. (2005). La Regenta. Madrid, España: Clásicos Castalia.

Blasco, V. (2004). Entre Naranjos. Madrid, España: Cátedra.

Bourdieu, P. (1983). Campo de poder y campo intelectual. Buenos Aires, Argentina: Folios.

Bourdieu, P. (2011). Las estrategias de la reproducción social. Buenos Aires, Argentina: Siglo XXI Editores.

Creswell, J. (1998). Qualitative Inquiry and Research Design. Choosing among Five Traditions. Londres, Inglaterra: Sage.

Foucault, M. (1977). Historia de la sexualidad. Madrid, España: Siglo XXI.

Rossman, G. \& Rallis, S. (1998). Learning in the field. An introduction to qualitive research. Londres, Inglaterra: Sage.

Vasilachis, I. (2006). Estrategias de investigación cualitativa. Barcelona, España: Editorial Gedisa.

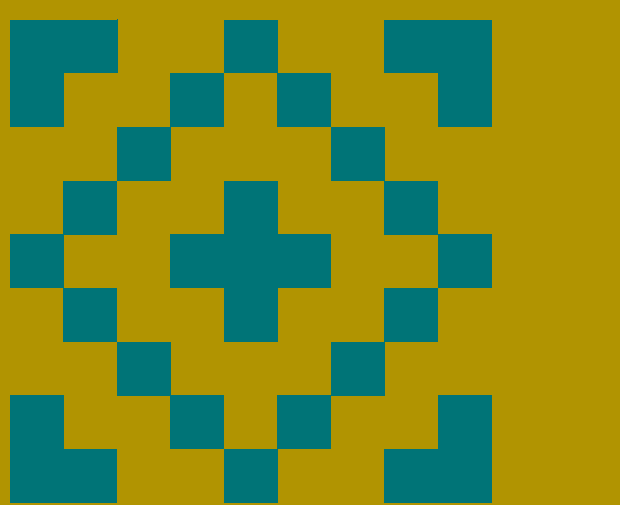

